\title{
Resemblance and Qualitativeness of Instances
}

\author{
Christer Svennerlind
}

\section{Introduction}

Classifications of ontologies generally set out from their recognition or rejection of universals. Thus, an ontology recognising universals is classified as being a realism, whereas an ontology rejecting universals is classified as a nominalism. Independently of its recognition or rejection of universals, a specific ontology may recognise properties or other categories as particulars. If it does, I recommend that it be classified as either a moderate realism or a moderate nominalism. According to the former, there are universals as well as particular instances of them. According to the latter, there are only particular instances. ${ }^{1}$

Various names have been given to the latter. Some of which are: "abstract particular", "aspect", "case", "concrete property", "instance", "moment", "trope", and "unit-property". The term which seems to be used most often nowadays is "trope". This is unfortunate, since it preferably forms associations with nominalistic views. Though the term "instance" has its own imperfections, it seems to be more neutral and therefore preferable to "trope" as general term. It will serve as my first choice in the rest of this article.

Moderate nominalism and moderate realism come in varieties. Moderate nominalism in particular can take many forms. Thus, there is need for supplementing the two generic designations, if transparency is sought regarding what specific versions of moderate realism or nominalism are being referred to. ${ }^{2}$

\footnotetext{
${ }^{1}$ The ontology of Ivar Segelberg, once Ingvar Johansson's PhD tutor, is of a hybrid form. It is a non-moderate realism with regard to relations but a moderate nominalism with regard to properties (cf. Segelberg 1999:240ff.; Svennerlind 2008: Ch. 4). "Moments" is his preferred term for property instances. It should be observed though that Johansson does not agree with this interpretation. He considers Segelberg to be a moderate nominalist with regard to properties as well as relations (cf. Johansson forthcoming). Johansson is himself a moderate realist (cf. Johansson 1989: Ch. 3).

${ }^{2}$ For more terminological niceties, cf. Svennerlind (2008:8-10).
} 
In what follows, the role given to resemblance in the ontology advocated by Arda Denkel is scrutinised. Judging by appearance, this ontology is a moderate nominalism.

\section{The Resemblance Thesis}

What is being described as a version of the resemblance account of properties is expounded and defended in Denkel (1989). To that end, a thesis ${ }^{1}$ called "the Resemblance Thesis" ("the RT", for short) is introduced:

The main contention of what has been characterized as the RT is that the 'common aspects' observed among things in nature, such as properties or kinds, ${ }^{2}$ are a matter of resemblance rather than identity. It is owing to such resemblances in different degrees that we are able to speak about 'common' properties and natures and thus classify the world accordingly. (Denkel 1989:37)

Asserted here is that a property or kind of one object is never numerically identical with a property or kind of another object. The properties or kinds of different objects are at most similar to each other; ${ }^{3}$ though it is not explicitly said here, I suppose they may even be exactly similar. The view put forward here is considered to be incompatible with Aristotelian, or immanent, realism. ${ }^{4}$ Denkel explicitly rejects universals in rebus.

\footnotetext{
${ }^{1}$ Denkel (sort of) borrows this thesis from John Locke (1961: Book III, Ch. III).

${ }^{2}$ That kinds are mentioned here, in combination with kinds being described as aspects of things, suggests a category besides that of instance of property. Such a category is indeed recognised by Johansson. "Substance-instance", or "instance of substance-quality", is his term (Johansson 1989: Ch. 3). With reference to Aristotle, another name for it might be "instance of secondary substance". Note that an Aristotelian primary substance is, in this sense of "instance", not an instance of a secondary substance. Instead, it is an instance of a fundamental state of affairs, this being the complete universal content of a primary substance. "Instance of a fundamental state of affairs" is Johansson's term. Also Donald Williams hints at a category of substance-instance, when asserting that there is a humanity trope in Socrates, another such trope in Napoleon, etc. (Williams 1953:10; 1986:5).

${ }^{3}$ An empirical argument is adduced: "What one needs to do in order to realize that the so-called identical properties are in fact merely similar is to examine them more closely. For example, magnifying every occurrence of the letter ' $a$ ' on this page will reveal that no two of them are fully identical in shape" (Denkel 1989:37).

${ }^{4}$ I take "immanent realism" to be an alternative to "Aristotelian realism". Since Denkel uses the latter, I will do so too.
} 
What about the role of the resemblance relation? Does it ground the qualitative content of its relata? If not, are instead the relata founding the resemblance relation? Evidently, these two positions are opposites of each other. However, the way Denkel expresses himself makes it somewhat difficult to establish which one of these two positions he is actually advocating. Or, is he perhaps in favour of yet a third position?

Denkel is not silent on the interpretation of the thesis of resemblance. We are informed that there are two ways in which it can be interpreted: "(a) in itself the world is as it is, but in perceiving it we see it as involving certain resemblances and classify it accordingly; (b) the world is so constituted that in it there are actual resemblances between particulars" (Denkel 1989:37). Since it recognises there being objective resemblances, the latter interpretation is considered a minimal form of realism. It is also the interpretation recommended by Denkel. He rejects views according to which resemblances among things are due to the biological, or Kantian, make-up of the perceptual apparatus of humans (Denkel 1996:159). Though this in itself is interesting, it does not settle the issue whether a resemblance relation is grounding or grounded vis-àvis its relata.

The use of the term "realism", just seen flashing by, gives cause for a comment. But before that comment is made, at bit more relevant information is added.

[W] hat distinguishes nominalistic views from realistic accounts is that while the latter explain properties and kinds ontologically, the former give epistemic-cognitive explanations and deny that anything more than this can be true of general terms. It follows that the realistnominalist distinction does not fully coincide with the question whether there are objective universals, where the latter is understood in the sense of multiply-applying principles. For properties and kinds can be granted extra-mental reality without this involving the claim that these exist identically in different particulars. (Denkel 1989:38)

Denkel's use here and elsewhere of "realism" and "nominalism", as well as their respective cognates, is not in complete harmony with the recommendations given by me in the introduction. Evidently, our principles of division are not the same. He does not take recognition of (extra-mental) universals a necessary condition for being a realist. He takes recognition of instances to be a sufficient condition for being a realist. Whereas he 
draws the line at the recognition of instances, I recommend that it be drawn at the recognition of universals. The universals he distances himself from are the extra-mental universals. It will be seen, from what is quoted below, that he recognises conceptual universals. Thus, he seems to consider conceptual universals not to be inconsistent with nominalism. What he actually says regarding conceptual universals is rather inexplicit though. Anyhow, I hope that the chaos resulting from mixing our respective terminologies is controllable.

Obviously, the exact interpretation of the resemblance thesis is still an unsettled issue. To get closer to an answer, lets move on to the respects in which entities are said to resemble one another.

\section{Respect of Resemblance}

Strictly speaking, the last statement of the last quotation ${ }^{1}$ is not incompatible with an Aristotelian moderate realism. The latter considers it possible for a universal to exist identically in different particulars. It does not consider it possible though for its instances to do so. The instances of moderate realism are as non-recyclable as the instances of any moderate nominalism.

Aristotelian realism takes universals to exist in rebus. One and the same universal can, at the same time, exist in more than just one object. Due to the fact that they share at least one universal property objects resemble one another. It is in the respect in which two objects share a universal that they resemble each other. ${ }^{2}$ Evidently, one object can resemble several other objects without the latter resembling each other in that same respect. The realist thesis can be paraphrased: "There is a need to mention the different respects in which the objects resemble one another. But to mention these respects [...] is to mention universals, i.e., to mention respects of identity" (Denkel 1989:39). Thus, a realist would say that resemblance presupposes universals.

\footnotetext{
${ }^{1}$ I.e.: "For properties and kinds can be granted extra-mental reality without this involving the claim that these exist identically in different particulars."

${ }^{2}$ There seems to be at least two ways in which we commonsensically use "resemble in respect of": (i) Two objects resemble each other in respect of $P$, and meant by that is that they share a determinate property under a certain determinable property, $P$; e.g., two objects resemble each other in colour since they are both red, colour here being the determinable and red the determinate. (ii) Two objects resemble each other in respect of $P$, and meant by that is that they share a property, $P$, period.
} 
Denkel stresses that two theses can be discerned in the view just reported on, and that the second thesis does not follow from the first.

The first [thesis] is that we cannot express different resemblances unless we mention the respects in which these resemblances are different. The second is the thesis that any specific resemblance is a partial identity such that specifying the respect of resemblance is specifying partial identity. Merely advancing the first thesis as argument cannot yield the desired reduction unless the second is also assumed as a premise or separately proved to be true. (Denkel 1989:39)

While the first thesis is about the need to specify the respects in which resemblances hold, as well as not hold, the second is about the nature of these respects. That we can distinguish resemblances is, according to Denkel, an epistemic-cognitive achievement of ours. However, our inability to distinguish without mentioning the respects of resemblance does not demonstrate what the realist claims. As an attempt to forestall, at least to some extent, misrepresentation of his more elaborate view on this central issue, I let Denkel speak for himself.

Indeed, granted that proper qualifications are made, the realist interpretation of the RT should not only admit, but should also positively claim that there are objective respects of similarity between things, independent of the classifying mind. I submit that this logically follows from a consistently realist interpretation of the RT. If properties are objective or 'real' resemblances among particular objects, and if as a matter of fact there are different properties, then there are different resemblances between objects. We specify and distinguish such objective differences by mentioning different respects in which objects resemble one another. This we do with the awareness that the mentioning itself involves general terms and concepts which are the products of the understanding. However, doing this does not entail more than the claim that, objectively, particulars are related by different resemblances. Certainly, it does not entail that such respects are iden- 
tities, or that they are abstract particulars independent of any resemblance between objects. ${ }^{1}$ (Denkel 1989:39-40)

In a footnote, inserted after the penultimate sentence, it is stated:

We need to distinguish the expression or conceptualization of such respects, from the objective respects themselves. That the former is general or multiply applicable by nature does not entail that what it is derived from (i.e., the latter) be also multiply applicable. As characterized here, 'objective respects of resemblance' constitute different particular relations of resemblance between two particulars: they are not second-order resemblances. Using another terminology, all 'determinables' are to be explained within the framework of Conceptualism. The objective aspects of resemblance can be the case at the level of ultimate 'determinates'. [...] On the other hand, the question whether indicating a respect of resemblance is indicating a property [...] does not arise here since the point of departure of the present paper is that properties are objective resemblances. (Denkel 1989:39-40n)

From the former of these two quotations, we learn that in accordance with the resemblance thesis there are objective respects of similarity between things. But what can be made of what follows thereafter? It is perhaps best to start with what is being asserted in the footnote, i.e., in the second quotation.

In the footnote, a distinction is made between, on the one hand, the expression or conceptualization of objective respects, and, on the other, the objective respects themselves. Denkel here gives expression to, what he would describe as, his conceptualism. It is inspired by Locke, whose famous words regarding the meanings of general terms Denkel refers to: "Nature, in the production of things, makes several of them alike; [... I think we may say, the sorting of them under names is the workmanship of the understanding, taking occasion, from the similitude it observes amongst them to make abstract ideas, and set them up in the mind, with names annexed to them, as patterns or forms [...], to which, as particular things existing are found to agree, so they come to be of that species, have that denomination or are put into that classis" (Locke 1961:Book

\footnotetext{
${ }^{1}$ It is difficult to know for sure what the message of the second part of the last sentence is. One interpretation is that the view expressed is that resemblances found the qualitative contents of their relata.
} 
III, Ch. III, Section 13; Locke's own italics). This is interpreted as maintaining that the mind has the capacity to form, from what are particulars, ideas that have general applicability. Furthermore, the resemblance thesis, in its ontological interpretation, is said to found this conceptualism (Denkel 1989:36f.).

Denkel more or less agrees with Locke, if this is what Locke in fact maintains. A potential objection against Locke is that he might be a (real) realist, after all.

There is reason for suggesting that in fact what Locke understood by resemblance was partial identity: according to him, degrees of resemblance between particulars depend upon the extent of qualitative identity. Such an understanding will reduce the 'realist' RT to an Aristotelian Realism. But surely, this is not the only way in which resemblances can be understood. (Denkel 1989:40)

Ironically, Denkel might agree with a "Lockean" view, which Locke himself does not embrace.

In Denkel (1996), more is said about conceptualism:

I believe that properties, relations ${ }^{1}$ and kinds are real, but not universal. One of the two rival positions I have contrasted [...], namely, that particular properties in the world are mutually related by nothing closer than resemblance, claims just that. It maintains that the socalled universals are creations of the mind that result from summarizing and grouping such objective resemblances. Hence my position is a combination of conceptualism and a realism of particular resembling properties. (Denkel 1996: 155)

It is asserted here that universals are only to be found in the mind. The mind "creates" universals "from summarizing and grouping [...] objective resemblances". What stops Denkel from saying, instead, that the mind abstracts universals from resembling properties? He seems certain of that concepts have extra-mental bases; the bases being, what he describes as, objective resemblances. However, he takes for granted that everything that exists extra-mentally is particular through and through.

\footnotetext{
${ }^{1}$ Here we see that Denkel considers also relations to exist as instances. Presumably, what he asserts here regarding properties applies also to relations and kinds.
} 
This premise prevents him from accepting the thesis that the mind abstracts what is already there in the first place, i.e., universals. ${ }^{1}$

Supposedly, an advocate of a cruder form of conceptualism would claim that the mind forms concepts without any objective bases. Presumably, having in view a conceptualism of this sort, Denkel asserts:

It seems very possible $[. .$.$] that there are properties which are not yet$ discovered by the human race. If the crude version of conceptualism were true, such a discovery ought not to be possible. On its own, the common conclusion of these criticisms, namely, that our concepts of properties must have extra-mental bases, does not establish a realism of universals. Many philosophers, with whom I find myself in agreement, will reject the latter doctrine, while they acknowledge the conclusion. The rationale of such a position is in the tenet that the objective bases of universal concepts are property instances, or particular properties that inhere in concrete things. (Denkel 1996: 156-7)

Here we see, apart from the implied rejection of crude conceptualism, again the rejection of there being universalia in rebus.

Equipped with these bits of information regarding Denkel's alleged conceptualism, lets return to the issue of respects of resemblances. That these respects are universals is something with which the next quotation, in a way, agrees.

We specify and distinguish resemblances by mentioning respects, but from the point of view of the Thesis of Resemblance the latter are simply general terms and concepts, hence products of the understanding. (Denkel 1996: 160; my italics)

Here, the respects of resemblance are said to be general terms and concepts. We know from an earlier quotation that these are "general or multiply applicable by nature". In reason, this is a circumlocution for these terms and concepts being universal. Turning it in this way, Denkel seemingly manages to deliver universal respects without surrendering to Aristotelian realism, since the universal respects referred to are not in the relata.

\footnotetext{
${ }^{1}$ Cf. Donald Mertz (1996), for a moderate realism of the sort hinted at here.
} 
However, other statements, made already in the paragraph directly following the one from which the former quotation comes, somewhat complicate the picture.

From the point of view of the present approach I see no threat in granting the existence of objective respects of resemblance. Once we declare that particular properties are objective, and that between them they resemble in the same sense of objectivity, it seems natural that we also allow objective respects of resemblance; though not necessarily, we may regard these as higher-order similarities. (Denkel 1996: 160-1)

The pronoun "these", of the last sentence, refers back to "the objective respects of resemblance". The objective respects of resemblance can thus be regarded as higher-order similarities. It is not evident how this "can be regarded as" is to be interpreted exactly. I take it though that Denkel considers the respects of resemblance relations to be, in some sense, higher-order resemblance relations.

On the face of it, that objective respects of resemblance are higherorder similarities is in conflict with what was asserted in an earlier quotation: "As characterized here, 'objective respects of resemblance' constitute different particular relations of resemblance between two particulars: they are not second-order resemblances"1 (Denkel 1989:39n). The former assertion - i.e., that the respects of resemblance are higher-order similarities - makes sense in itself though, given that the resemblances between objects ground their qualitative contents. However, the sense it makes will evaporate if the implicated view is vulnerable to an argument made famous by Bertrand Russell.

\section{The Resemblance Thesis and Russell's Regress Argument}

In Russell (1912:Ch.11), ${ }^{2}$ a regress argument is presented, the alleged moral to be learnt from it being that universals cannot be dispensed with.

\footnotetext{
${ }^{1}$ The verb "constitute" may have here the meaning of "ground". If that is its intended meaning, Denkel is here saying that particulars, which are the relata of various resemblance relations, ground these resemblance relations, not the other way round.

${ }^{2}$ Versions of the argument are to be found also in Russell (1903:348-9; 1911:9). Essentially the same argument appears in John S. Mill (1943:117n).
} 
Denkel is of course familiar with the argument. The following is his rendering of it.

According to Russell, in the RT there is an implicit but inevitable appeal to the universality of resemblance. [...] According to the RT, a quality, for instance, is a similarity between particulars. But, [...] particulars have many different respects of similarity. So the question arises as to what it is that makes, for instance, the unity of the class of blue things as opposed to the class of red things. The answer will have to be that a pair of blue things has the same relation of resemblance to another pair of blue things, but not to pairs of red things. Or, alternatively, a blue thing has the same relation of resemblance to all other blue things but not to red things. But if what we have here is the same relation of resemblance in a diversity of particular things or circumstances, we have a genuine universal. Russell adds that little will be changed by saying that only a resemblance (and not an identity) exists between resemblances: resembling resemblances would still be universals. (Denkel 1989:43)

The argument can be reconstructed as taking as its point of departure that it needs to be explained why blue things are blue, red things are red, etc. According to nominalism, it cannot be the universal blueness, the universal redness, etc., respectively. This since none of these universals is "available". Left are (perhaps) different, specific resemblance relations for blue things, for red things, etc. Each specific resemblance relation brings about the unity of its class of things. However, since the same blueness resemblance relation now relates more than just one pair of relata, ${ }^{1}$ and the same holds for the redness resemblance relation, as well as for all the other specific resemblance relations, each one of these specific resemblance relations seems to be a universal. These universal resemblance relations must be taken care of in some way. The way to do that seems to be to consider each pair of resemblance relata to be related by its own particular resemblance relation. But then the unity among the members of each class of particular resemblance relations is in need of explanation. The way to explain the unity seems to be to invoke a resemblance relation holding between the particular blueness resemblance

\footnotetext{
${ }^{1}$ That a regress ensues for each type of property, relation and kind, is perhaps fully visible not until there are three instances of the type of property, relation or kind.
} 
relations, another holding between the redness resemblance relations, etc. Evidently, the regress does not stop here. The moral of this is: to get rid of a universal, another universal must be invoked, ad infinitum.

Denkel's riposte, as designed in Denkel (1989), to Russell's argument is found essentially in the following quotation.

[T] he unity of the class of blue things can be given in terms of the resemblances between a given aspect of a particular object to particular aspects of different objects, and this would not be a sameness among diverse things. More specifically, given any object which is a member of this class, there is a particular aspect this object possesses (the patch on its surface which we call 'blue'), and this aspect resembles a particular aspect (the blue patch on the surface) of every other object which is a member of this class. So, any object arbitrarily chosen from the class is related by particular resemblances to every other object in the class. Notice that in this description no mention is made of 'the same resemblance' recurring in a number of particular resemblances. The unity of the class is not grounded upon such a sameness, which would be to introduce a universal. The unity of these particular resemblances is assured by their linking one and the same particular aspect of the same object with particular aspects of other objects. The aspects of those objects do make the desired unity, i.e., they are all what we ordinarily call 'blue', if they resemble the aspect of the object chosen arbitrarily, which ex hypothesi happens to be blue.

So, on the present account, the principle of unity is not the sameness or resemblance of relations. It is the sameness of a singular aspect which constitutes one of the terms of all such relations. (Denkel 1989:44-5)

What is being stated here gives rise to an obvious objection. Presumably, "aspect" is a term covering the same territory as "instance of property" - as well as "instance of kind", and "instance of relation". Then, if patches are taken as aspects of objects, they are dubious ones. This since each patch has (at least) colour, extension, and form; i.e., each one is (at least) a two-dimensional object. But perhaps by "patch" is not meant more than by, e.g., "colour", or "blue".

Another objection is that two quite different theses seem to be asserted in the first paragraph of the quotation. One of them implies that a specific aspect of one specific member of the class of, say, blue things has a 
privileged position. It is, so to say, the standard blue-aspect. The unity of the class is due to that each blue-aspect of the other members of the class are linked by resemblance relations, all of which are particulars, to that specific blue-aspect. ${ }^{1}$ This is being asserted also in the second paragraph of the quotation. The other thesis, which seems to be extractable from the first paragraph, does not imply anything about a certain aspect having a privileged position. Instead, unity is due to that resemblance relations, all of which are particulars, link all the blue-aspects of the members of the class.

The version with one privileged aspect has affinities with the resemblance nominalism of H. H. Price (1953: Ch. 1). Unlike Price, according to whom, there must be at least three objects making up a group of privileged objects, Denkel is satisfied with just one single object with its relevant aspect. Although it is not explicitly asserted, I take it that the reason for that is that the aspects are supposed to be simple. The aspects being simple entities, Denkel thinks that the problem Price intends to take care of with his group of standard objects does not arise. The problem being that the complexity of ordinary objects, which are the entities Price are working with, complicates what the relevant respect of similarity is. With simple entities this problem seemingly does not arise.

I would say that it does not make any big difference which one of the two mentioned theses Denkel actually embraces. They have one essential assumption, or postulate, in common. It is that the specific qualitativeness of each aspect is something given; i.e., not something that is the result or consequence of anything else. If this is indeed assumed, resemblance relations will not be looked upon as grounding the qualitativeness of aspects. Instead, the resemblance relations will be looked upon as being grounded by their relata. ${ }^{2}$

However, remember that Denkel asserts that the respects of resemblance relations can be regarded as higher-order resemblance relations. This gives support to the hypothesis that what he advocates is the thesis that resemblance relations found the qualitative contents of their relata.

\footnotetext{
${ }^{1}$ Aspects are the primary relata of resemblance relations. The objects they inhere in are derivatively similar to each other (cf. Denkel 1996: 154).

${ }^{2}$ Cf. Keith Campbell (1990) and Anna-Sofia Maurin (2002). They both advocate that resemblance is founded on relata, and this because of that the qualitativeness of the latter is something given.
} 
That would be the aspects of objects. But, if that is indeed the case, it is difficult to see how that view can steer clear from the pitfall of Russell's regress argument.

\section{Concluding Remarks}

I have tried to show that what is asserted in Denkel $(1989 ; 1996)$, regarding the role of resemblance, points in two different directions. What is advocated are two views that are opposites of each other. I would also say, though tentatively, that there is a latent moderate realism in Denkel. And that the latter might be a hidden factor, which at least partly explains why he does not consider Russell's regress argument to be a threat to his alleged nominalistic position.

\section{References}

Campbell, Keith (1990). Abstract Particulars, Oxford: Basil Blackwell.

Denkel, Arda (1989). "Real Resemblance", The Philosophical Review, 39:36-56.

Johansson, Ingvar (1989). Ontological Investigations. An Inquiry into the Categories of Nature, Man and Society, $1^{\text {st }}$ ed., London: Routledge $\left(2^{\text {nd }}\right.$ enlarged ed., Frankfurt: Ontos Verlag, 2004).

Johansson, Ingvar (forthcoming). "On Converse Relations - What We Can Learn from Segelberg's Controversies with Russell and Moore."

Locke, John (1961). An Essay Concerning Human Understanding, London: Dent ( $1^{\text {st }}$ ed., London: Printed for Thomas Bassett, 1689).

Maurin, Anna-Sofia (2002). If Tropes, Dordrecht: Kluwer Academic.

Mertz, Donald (1996). Moderate Realism and Its Logic, New Haven: Yale University Press.

Mill, John Stuart (1843). A System of Logic Ratiocinative and Inductive, London: Longmans.

Price, Henry H. (1953). Thinking and Experience, London: Hutchinson's University Library.

Russell, Bertrand (1903). The Principles of Mathematics, Cambridge: Cambridge University Press.

Russell, Bertrand (1911). "On the Relations of Universals and Particulars", Proceedings of the Aristotelian Society, New Series, 12:1-24. 
Russell, Bertrand (1912). The Problems of Philosophy, London: Oxford University Press.

Segelberg, Ivar (1999). Three Essays in Phenomenology and Ontology, H. Hochberg \& S. Hochberg Ringström (transl.), Stockholm: Thales.

Svennerlind, Christer (2008). Moderate Nominalism and Moderate Realism, Göteborg: Acta Universitatis Gothoburgensis.

Williams, Donald C. (1953). "On the Elements of Being: I", The Review of Metaphysics, 7:3-18.

Williams, Donald C. (1986). "Universals and Existents", Australasian Journal of Philosophy, 64:1-14. 


\section{The Measurement-Theoretical Approach to Intentionality}

Erwin Tegtmeier

\section{The Problem of Intentionality}

Intentionality is the connection between a mental state and an object (I will mostly talk instead of "objects" of "intentions" in order to admit objects which are not things, such as facts) on which our knowledge of the world, including ourselves, is based. The philosophical problem of intentionality consists in two questions: 1 . What is the categorial structure of intentionality? 2. Does the categorial analysis of intentionality entail that we know the world (the totality of existents)? Or even more briefly: do we know the world? The second question is the key question of philosophical epistemology. A positive answer is not equivalent to epistemological realism. It is compatible with idealism as well as epistemological realism. Realism is distinguished from idealism by the claim that the world is independent of the knowing subject. According to idealism the world we know depends on the knowing subject.

The term "intentionality" adopted from medieval philosophy suggests that the object is in the mind. Brentano who introduced or reintroduced the term was misled originally by it into thinking that the object is literally in the mind, that it is a real part of the mental act which is directed to it. Soon, he realised that the object is never part of the act itself even if the object is mental. And henceforth his main aim was to develop his ontology of relations in such a way that he could do justice to the intentional connection between act and object. At first, Brentano held that intentionality is not a relation but only resembles a relation. Later on, he arrived at the view that it is a genuine relation while many entities categorised by Aristotle as relations, such as relations of comparison, are not. ${ }^{1}$

In contrast to Brentano, Meinong distinguishes the mental act's content from its object. He takes the content to be a part of the mental act and to stand in the intentional relation to the object. Besides the content

\footnotetext{
${ }^{1}$ The Husserlian tradition stays with the earlier view, see, for example, Johansson (2004:205f).
} 
and the object of a mental act or state there is, of course, the accompanying brain state and the linguistic expression of the mental act as well as the linguistic representation of the object.

\section{Representationalism (Locke)}

The theory of measurement whose application to the phenomenon of intentionality we want to consider here, is also called "representational theory of measurement". It is not the only, but certainly the most widely accepted, current theory of measurement. This theory derives (as the name mentioned correctly suggests) indirectly via intermediaries from representationalism, an influential theory of knowledge which is attributable mainly to John Locke. It follows Descartes' new way of ideas, i.e. the introduction of ideas as mediators between mind and the world. Ideas serve as representatives of objects. The mind attends to them in order to know the objects which they represent. Ideas are assumed to be similar to the objects they represent. ${ }^{1}$ Descartes' and Locke's ideas are in the mind and mental. Plato's were not. According to the representationalist theory of knowledge it is similarity (the similarity between ideas and their respective objects) which connects the mind to the world.

Representionalism furnishes a connection between the mind and the world. This connection, however, is a composition of two different relations, the relation of attending between a mental state and an idea and the relation of similarity between the idea and the proper object of the mental state. The first acquaints with ideas, the second not with objects, since the similarity between two terms does in no way imply that one term is acquainted with the other. Similarity is simply not a relation of acquaintance. Therefore, representationalism implies that we are not acquainted with the world but only with ideas in the mind and that we depend on an inference from ideas to objects which were mere conjectures. Representationalism clear led to scepticism.

Representationalism met with a devastating contemporaneous objecttion: we cannot know whether an idea represents since we know what it represents only by way of the idea and not independently of it ( $\mathrm{J}$.

\footnotetext{
${ }^{1}$ A view that Cartesians had strongly rejected because of the categorial disparity between mind and body which they assumed. The intentional connection between the mental and the physical remained a mystery for them.
} 
Seargent). ${ }^{1}$ We know what we are acquainted with and what is inferable from it. Sergeant's objection means that under the premises of representationalism no inference to the objects is possible. Hence, representationalism leads to a negative answer to the second question of the problem of intentionality. It does not solve the problem.

\section{Structural Representationalism (Wittgenstein)}

Locke brought out already the ubiquity of relations and that many ideas which seem absolute turn out to be relational on closer inspection. In the 19th Century the view arose among the few epistemological realists that only the structure but not the content of the world is represented in the mind. This was adapted by the early Wittgenstein to an epistemology without minds. Wittgenstein substituted mind by language and advanced the theory that language represents and pictures the world by being structurally similar to it, more precisely: a sentence as fact pictures another normally non-linguistic fact by sharing its logical form. With respect to the problem of intentionality structural representationalism is not better off than idea representationalism. Sergeant's devastating argument still applies: we would not know that there is a structural similarity between language and world if we knew the world via language and had no language-independent access to the world.

Wittgenstein's and Carnap's structuralism prompted Tarski's theory of models ${ }^{2}$ which is part of the semantics of formalised theories. Models of a theory are algebraic structures (consisting of a carrier set and relations between its members), in which the axioms of the theory hold. The theory is not conceived of as a structure. Thus structural similarity can only hold between models and not between theories and models. Nevertheless, there is a hidden structural representationalism in model theory. It is revealed by the formalisation of language which reduces it to its logical form and the axiomatisation of theories which aim at bringing language and model into line in order to infer structural properties of the models from structural properties of the formalised language. Because of the reduction of language to its logical form there is always more than one model for a theory. The models investigated by model theory are

\footnotetext{
${ }^{1}$ Sergeant (1697).

${ }^{2}$ W. Stegmüller explicated Wittgenstein's picture theory in terms of the theory of models, see Stegmüller (1966).
} 
mostly mathematical, numerical structures. One of its results concerns categorical theories, i.e. theories the models of which are all isomorphic to each other. Isomorphism could be characterised informally as exact structural similarity which demands that there are same number of members of the carrier set in the respective structures.

\section{The Representational Theory of Measurement}

It was on results concerning categoricity that the representational theory of measurement has been built. D. Scott and P. Suppes first applied model theory to problems of metrisation and measurement. ${ }^{1}$ The key idea was that in measurement or rather in metrisation (i.e. the foundation and construction of scales of measurement) an empirical structure (the relations of which derive from measuring operations) is represented by a numerical structure isomorphic (or homomorphic) to it. An empirical structure is conceived of as an $n+1$-tupel of a set of objects $O$ to be measured and of empirical relations $R_{1}, \ldots, R_{n}$ between those objects, a numerical structure as an $n+1$-tupel of the set of real numbers $C$ and number relation $\mathrm{S}_{1}, \ldots, \mathrm{S}_{\mathrm{n}}$.

I argued elsewhere that the representational theory of measurement is fundamentally flawed. In a book and several papers I attacked this theory as operationalistic and positivistic and offered as an alternative an epistemologically realistic theory of measurement. ${ }^{2}$ In the book I also showed in detail the inadequacy of the axiomatic analysis of scientific concept formation which is constitutive of the representational theory of measurement.

If the representational theory of measurement is wrong, so is its application to intentionality. However, we do not have a simple and straightforward case of application. The relation of this theory of measurement and the respective analysis of intentionality will also have to be clarified here. Clearly, this theory of measurement is not exposed to Sergeant's anti-representionalist argument since the represented (the object with the empirical relations) as well as the representative (the numerical structures) are assumed to be given. However, the representational theory of measurement is not meant to be a philosophical theory

\footnotetext{
${ }^{1}$ Scott \& Suppes (1958).

2 Tegtmeier (1981, 1996, 1996/7).
} 
of knowledge. It cannot explain our primary cognitive access to the world as a theory of intentionality must do.

\section{Measuring Internal States}

The measurement theoretic approach to intentionality initiated by $\mathrm{D}$. Davidson ${ }^{1}$ does not explicitly address the philosophical problem of intentionality as explained in the beginning. It rather resembles more the measuring of psychological states by verbal behaviour. There is talk about the representation of intentional states by propositions (i.e. sentences) and one expects an explanation of the expression relation between intentional states and propositions as well as an explanation of the inference from utterances to intentional states.

The use of overt verbal behaviour as indicators of internal and unobservable internal states of other persons is customary and basic in human life, of course. Similarly, psychology uses reactions to sentences in questionnaires. There have been developed methods of testing and validating questionnaires, i.e., of deciding whether the reactions are closely enough related to the internal states to be inferred. These standard methods of psychology (called "test theory") are not translatable into the representational analysis of measurement because they involve an inference to unobserved underlying entities. The representational analysis, however, presupposes a positivistic view according to which measurement is numerical mapping of empirically given structures.

What I am driving at is that the representation of intentional states by sentences and the expression of intentional states by sentences, respectively, cannot be the subject of the measurement theoretic approach, although, the comparison between the role of numbers and sentences (propositions) and other formulations suggest the opposite. One reason for my claim has been explained above: the representational theory of measurement is not applicable. Now, the advocates of the measurement theoretic approach see only an analogy between numerical measurement and the representation of intentional states by propositions, but that is due to the representation not being numerical, a difference which is not relevant for my point. A second reason is that the approach does not deal with intentionality in the traditional sense although it is meant to do just that.

\footnotetext{
${ }^{1}$ Davidson (1974). An overview of the measurement theoretic and other naturalistic approaches to intentionality is given by Beckermann (1992).
} 
Intentionality in the traditional sense does not involve the relation between internal states and their linguistic expression but only the relations between internal states and the object to which they are directed.

\section{Intentionality and Propositions}

As the measurement theoretical approach is of no use in measuring internal intentional states, one has to turn to the alternative version of that approach, namely as an analysis of intentionality. If it is taken to be an approach to intentionality, the question arises: what does it imply then concerning intentionality? It implies that intentionality is an affair between intentional states and propositions, where propositions are not fact-like abstract entities but sentences or, more precisely, types of sentences. And it implies that an intentional state is directed to a certain proposition in virtue of the similarity between its causal role to the logical role of the proposition. In case of perceiving blue letters on a piece of paper this means that what is perceived is the sentence "those letters on the paper are blue". However, the advocates of the measurement theoretical approach do not consider perception, but mostly only belief.

The question which immediately poses itself is, of course, where the fact that the letters are blue is in that analysis of intentionality, or, at least, where the things (the letters and the paper) are in the analysis. The position is strange, indeed. We are supposed to be only acquainted with language. What is knowable is nothing but language signs. The position does not seem to be representationalist, since it is not assumed by the advocates of the measurement theoretical approach that the sentence (proposition) is merely a representative and only the mediate and the mediate intention, not the ultimate intention. It is taken to be the ultimate intention although the existence of (non-linguistic) things is not denied.

The position seems less strange if one takes into account its nominalist background. Influenced by Quine and Goodman, Davidson and other advocates of the measurement theoretic approach do neither countenance universals, nor tropes. Rather they explain that the predicate expression in a sentence does not represent anything at all and that what a sentences such as "the ink in the bottle is royal blue" makes true is a relation between an object (the ink in the bottle) and a predicate expression ("royal blue"). This is nominalism in the literal sense which has been very rare in the history of philosophy. In the Scholastic period the view that 
predicates are mere sounds (flatus vocis) was attributed only to Roscelin. However, in contemporary analytic philosophy it is the dominant view even though this view is very weak, actually hopeless. ${ }^{1}$

If there are no properties but only general terms, there is no complex on the side of the object (thing), neither a bundle of tropes (i.e. particular properties) or of general properties, nor facts consisting of individuals and general properties (universals). Hence, there is no object (in the sense of the phenomenologists' distinction between act and object), no intention of an intentional state and no intentional relation between both sides. The sentence which represents the intended fact is not a serious candidate of an intention. And this is not only because, as was pointed out, it is in most cases not something linguistic which we intend. Rather, with sentences the problem of universals recurs since we are talking about sentence types, of course, and thus about qualitative sameness between sentences. Hence, types raise the problem of universals again Linguistic philosophers wrongly think that an appeal to the linguistic distinction between types and tokens already solves the problem of universals. The problem recurs with the questions: "what are types?", "what are tokens?" and "how are they related?". Therefore, literal nominalism leads to the fallacy of idem per idem of appealing to the sameness of linguistic signs to ground the sameness of linguistic signs.

The reasons for taking propositions (sentences) as objects (intentions) of intentional states and their validity is one matter, another matter is the question whether the measurement theoretical approach can be diagnosed as representationalist. Two important differences between the original representationalist model and the measurement theoretical approach have emerged. Firstly, in the former representative and object are two, in the latter the representative becomes the object. Secondly, in the former the relation to the representative is acquaintance, in the latter it is merely structural similarity and thus much less close.

It can be said in favour of this diagnosis that the original representationalism itself soon arrived at an assimilation of the object to the representative. In Locke and Hume physical objects are more or less identified with complexes of sense data. That paved the way to Berkleyan and Kantian idealism. Kant does nothing but restating Seargent's objection

\footnotetext{
${ }^{1}$ This has been shown in detail with respect the literal nominalism of Goodman, Sellars, Quine, Davidson, Putnam by Herbert Hochberg, cf. Hochberg (1984).
} 
by his claim that the thing in itself is unknowable. Thus in turning the representative into the object (intention) the measurement theoretical approach merely follows the way of representationalism to the end. As to the relation with the representative, the difference between the measurement and the classical representationalist views is easily explained in representationalist terms. The representatives of classical representationalism are mental and in the mind, while the representatives of the measurement theoretical approach are mainly physical and outside of the mind, namely acoustical or geometrical signs. Concerning physical objects in general, classical representationalism agrees that our cognitive relation to them is based on similarity only and is not an acquaintance.

The diagnosis of the measurement theoretical approach as representationalist is also supported by its connection to nominalism. Like the measurement theoretical approach classical representationalism was the consequence of the rejection of universals. The representationalism of Locke is the consequence of the medieval nominalism of Occam. ${ }^{1}$ The two views differ only according to their choice of kind of representatives. Classical representationalism rejects universals in favour of ideas or concept, the measurement theoretical approach rejects universals in favour of predicate expressions and sentences.

How comes that the representative becomes the object? That diverges also from representationalism and is inconsistent with my claim that the measurement theoretical approach is representationalist. A comparison between the representationalist and the measurement theoretical analyses of knowing is revealing. To the idea of representationalism corresponds the sentence (proposition). According to the former analysis an intentional state is supposed to attend to a (mostly complex) idea while according to the latter there is merely a structural similarity. As was pointed out already, attending implies acquaintance, similarity does not. Ideas are taken to resemble things, sentences, which correspond in the measurement theoretical approach to ideas, in way round off things. Simple things or qualities are less plausible intentions of knowledge than complexes of things and qualities, i.e. facts. And sentences (propositions) are in linguistic philosophies the substitutes of facts. Thus the measurement theoretical approach is principally a kind of representa-

\footnotetext{
${ }^{1}$ For the connection between nominalism and representationalism see Bergmann (1967).
} 
tionalism. However, whether the measurement theoretical approach is representationalist or not, at any rate Sergeant's objection can be brought forward against it since it relates the intentional state to its object exclusively by similarity.

\section{Relational Elimination of Intentionality}

The representational theory of measurement has also an eliminative interpretation. It can be taken to show how numbers are dispensable in principle. Measurement values are reduced to positions in structures of empirical relations between objects of measurement. Weighing 2 kilogram, e.g., reduces to balancing a duplicate of the standard kilogram object and another such duplicate on a beam balance. Similarly, sentences as indications of brain or mental states can be eliminated in favour of the causal roles of brain states, i.e., positions of them in the causal structure. The result is that in the context of the theory of intentionality mental states or brain states are denied any connection other than that to other mental or brain states. Instead of the reference of the perceptual state of our example to the fact that the letters are blue or the indication relation to the sentence "the letters are blue", we allegedly need only such facts as the causal relation of that state to that of thinking that the text was processed by a certain computer program. Davidson seems to countenance also the eliminative version.

Why this cutting of connections to sentences and to objects? Apart from the relationism of measurement theory which is strongly influenced by E. Mach (who tried to relationise all absolute determinations) in this respect, Davidson here follows the lead of Quine's holism. ${ }^{1}$ Like Quine he rejects and dissolves the reference of words and sentences and mental states. Remember also the slogan of the later Wittgenstein: don't look for the meaning, look for the use!

There are, of course, not only causes but also reasons (arguments) for Quine's and Davidson's rejection of reference. Not only do they think that reference is dispensable but also that it leads into grave difficulties which cannot be removed. The discussion of those difficulties is the proper place to decide whether there is reference or not, but here is, of

\footnotetext{
${ }^{1}$ Davidson (1969).
} 
course not that place, that would be another subject. I am convinced that the difficulties of reference can be overcome. ${ }^{1}$

\section{What is Wrong with the Measurement-Theoretical Approach?}

Restricted to internal states reference is the same as intentionality, as the directedness of internal states. Basically, Davidson holds that intentionality is an illusion. This view does not seem to go with the attempt to offer structural similarity as a foundation for intentionality. Instead of explaining that the internal state $\mathrm{s}$ intends sentence $\mathrm{p}$ because of a similarity in their respective roles, Davidson should declare outright that what underlies the illusion of directedness is just the causal role of the internal state. However, that would not fit well into the program of "naturalising intentionality", i.e. to analyse intentionality in such a way that it applies also to brain states and hence would be compatible with materialism. The measurement theoretical approach follows that program.

An advocate of the measurement theoretical approach need not share Davidson's holism and might take intentionality seriously. However, both versions of the approach the eliminative and the one relying on structural similarity entail a negative answer to the key question of philosophical epistemology and thus the conclusion that we don't know the world. The consequence is scepticism and agnosticism which is, indeed, the epistemological attitude we find in Quine and Davidson.

\section{References}

Beckermann, A. (1992). "Das Problem der Intentionalität - Naturalistische Lösung oder meßtheoretische Auflösung", Ethik und Sozialwissenschaften, 3:462-465.

Bergmann, G. (1967). Realism: A Critique of Brentano and Meinong, Part II, Madison: University of Wisconsin Press.

Davidson, D. (1969). "True to the Facts", The Journal of Philosophy, 66:748-764.

Davidson, D. (1974). "Belief in the Basis of Meaning", Synthese, 27: 309-323

Hochberg, H. (1984). Logic, Ontology, and Language: Essays on Truth and Reality, München: Philosophia.

\footnotetext{
${ }^{1}$ For a short overview see the introduction to Hochberg (1984).
} 
Johansson, I. (2004). Ontological Investigations. An Inquiry into the Categories of Nature, Man and Society, $2^{\text {nd }}$ enlarged ed., Frankfurt: ontos verlag ( $1^{\text {st }}$ ed. London: Routledge, 1989).

Scott, D. \& P. Suppes, P. (1958): "Foundational aspects of theories of measurement", Journal of Symbolic Logic, 23:113-128.

Sergeant, J. (1697). Solid Philosophy Asserted against the Fancies of the Ideaists, originally published in London, 1697; repr. New York: Garland, 1984.

Stegmüller, W. (1966). "Eine modelltheoretische Präzisierung der Wittgensteinschen Bildtheorie", Notre Dame Journal of Formal Logic, 7:181-195.

Tegtmeier, E. (1981). Komparative Begriffe: Eine Kritik der Lehre von Carnap und Hempel, Berlin: Duncker \& Humblot.

Tegtmeier, M. (1996). "Kritik der modelltheoretischen Analyse des Messens", in V. Gadenne \& H. J. Wendel (eds.), Rationalität und Kritik, Tübingen: Mohr, 123-130.

Tegtmeier, E. (1996/7). "Meinong on Measurement", Grazer Philosophische Studien, 52:161-171. 